\title{
LIQUID-LIQUID PARTITION BEHAVIOR OF AMMONIA AND AMMONIUM ION BETWEEN HEXANE CONTAINING TRIOCTYLPHOSPHINE OXIDE AND AQUEOUS PERCHLORATE SOLUTIONS
}

\author{
Tatsuya SEKINE, Hi romi HISHIKURA, and Satoshi KUSAKABE \\ Department of Chemistry, Faculty of Science, Science University of \\ Tokyo, Kagurazaka, Shinjuku-ku, Tokyo 162
}

\begin{abstract}
Distribution of ammonia and ammonium ion between hexane containing trioctylphosphine oxide(TOPO) and aqueous 1 mol $\mathrm{dm}^{-3}$ sodium perchlorate-chloride media at $298 \mathrm{~K}$ was studied. The distribution ratio of ammonia was very low and independent of TOPO but that of ammonium ion was third order dependent on this extractant and it was higher than those of sodium(I) and potassium(I) under the identical conditions.
\end{abstract}

In the course of a series of work on the solvent extraction behavior of metal ions as perchlorates with a solvating type extractant, trioctylphosphine oxide (TOPO), in hexane, ${ }^{1-3)}$ it was observed that ammonium perchlorate was extracted to some extent but ammonia was only poorly. Since ammonium ions are often found in several sample solutions which are treated by solvent extraction with extractants of this type, measurements of their distribution ratios in hexane-aqueous perchlorate solution systems have been carried out at $298 \mathrm{~K}$ and a consideration about the equilibria involved in these systems has been made.

\section{Experimental}

Experiments were carried out in a thermostated room at $298 \mathrm{~K}$ in a similar way as previously described. ${ }^{1-3)}$ The sodium perchlorate was prepared from sodium carbonate and perchloric acid and recrystallized several times from water. Aqueous $1 \mathrm{~mol} \mathrm{dm}^{-3}$ sodium perchlorate or sodium perchlorate-chloride solutions containing ammonia were prepared and the concentration of ammonia was determined by titration and those of sodium salt solutions by gravimetry. Ammonium perchlorate solutions or mixed solutions of ammonia and ammonium perchlorate were prepared from these solutions by adjusting the hydrogen-ion concentration with perchloric acid. The total concentration, $\left[\mathrm{NH}_{3}\right]+\left[\mathrm{NH}_{4}{ }^{+}\right]$, in the initial aqueous phase was $0.1 \mathrm{~mol} \mathrm{dm}^{-3}$. A portion of the aqueous solution containing ammonia and/or ammonium perchlorate and the same volume of hexane containing a certain amount of TOPO were placed in a stoppered glass tube. The two phases were agitated for ten minutes and separated by centrifugation. Aliquots from the two phases were pipetted and transferred into other tubes so carefully that no escape of ammonia to the gas phase occurred. The organic phase was washed with $1 \mathrm{~mol}^{-3}$ 
nitric acid to back-extract the ammonia or ammonium ions extracted into the organic phase. An amount of sodium hydroxide solution was then added to these aqueous solutions and the total ammonia was determined by an ammonia electrode (TOA Electronics, AE-235). The hydrogen-ion concentration was measured potentiometrically by using a solution contajning $1.00 \times 10^{-2}$ mol $\mathrm{dm}^{-3}$ perchloric acid and $0.99 \mathrm{~mol} \mathrm{dm}^{-3}$ sodium perchlorate as a standard; thus it was obtained in the stoichiometric units.

\section{Statistical}

The distribution ratio of total ammonia may be written as

$$
\mathrm{D}\left(\mathrm{NH}_{3}+\mathrm{NH}_{4}^{+}\right)=\frac{\left[\mathrm{NH}_{3}\right]_{\text {org,total }}+\left[\mathrm{NH}_{4}^{+}\right]_{\text {org,total }}}{\left[\mathrm{NH}_{3}\right]+\left[\mathrm{NH}_{4}^{+}\right]}
$$

where "org" denotes those species in the organic phase and "total" denotes the total concentration of the material. either solvated or unsolvated with TOPO in the organic phase. Since it was found from the results that the species in the organic phase were unsolvated ammonia and trisolvated ammonium perchlorate, only these two species will be treated statistically here.

The distribution equilibria can then be written as

$$
\begin{aligned}
& \mathrm{NH}_{3} \rightleftarrows \mathrm{NH}_{3}(\mathrm{org}) \\
& \mathrm{K}_{\mathrm{d}}=\left[\mathrm{NH}_{3}\right]_{\mathrm{org}\left[\mathrm{NH}_{3}\right]^{-1}} \\
& \mathrm{NH}_{4}{ }^{+}+\mathrm{ClO}_{4}^{-}+3 \mathrm{TOPO}(\mathrm{org}) \rightleftarrows \mathrm{NH}_{4}(\mathrm{TOPO})_{3}{ }^{+} \mathrm{ClO}_{4}^{-}(\mathrm{org}) \\
& \mathrm{K}_{\mathrm{ex}, 3}=\left[\mathrm{NH}_{4}(\mathrm{TOPO})_{3}{ }^{+} \mathrm{ClO}_{4}^{-}\right]_{\mathrm{org}}\left[\mathrm{NH}_{4}^{+}\right]^{-1}\left[\mathrm{ClO}_{4}^{-}\right]^{-1}[\mathrm{TOPO}]_{\mathrm{org}}{ }^{-3}
\end{aligned}
$$

The equilibrium between ammonia fnd ammonium ion is written as

$$
\begin{aligned}
& \mathrm{NH}_{4}^{+} \rightleftarrows \mathrm{NH}_{3}+\mathrm{H}^{+} \\
& \mathrm{K}_{\mathrm{a}}=\left[\mathrm{NH}_{3}\right]\left[\mathrm{H}^{+}\right]\left[\mathrm{NH}_{4}^{+}\right]^{-1}
\end{aligned}
$$

From Eqs. 2 to 4 , Eq. 1 can be rewritten as

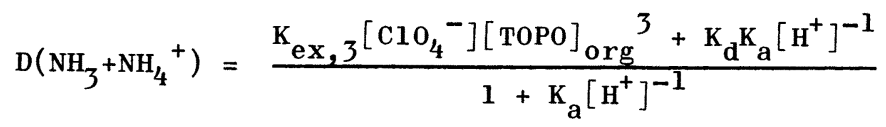

Sodium perchlorate and perchloric acid are also extractable with TOP0 from acid sodium perchlorate solutions ${ }^{1}$ ) but since the hydrogen-ion concentration is not: high, and consequently the concentration of perchloric acid is low, this effect of acid extraction is calculated to be negligible under the conditions of this study. 
For this reason, only the decrease in the free TOPO concentration due to the extractions of sodium perchlorate and ammonium perchlorate is corrected on the basis of the following equilibrium constant

$$
\begin{aligned}
& \mathrm{M}^{+}+\mathrm{ClO}_{4}^{-}+3 \mathrm{TOPO}(\mathrm{org}) \rightleftarrows \mathrm{M}(\mathrm{TOPO})_{3}{ }^{+} \mathrm{ClO}_{4}{ }^{-}(\mathrm{org}) \\
& \mathrm{K}_{\mathrm{ex}, 3(\mathrm{M})}=\left[\mathrm{M}(\mathrm{TOPO})_{3}{ }^{+} \mathrm{ClO}_{4}{ }^{-}\right]_{\mathrm{org}}\left[\mathrm{M}^{+}\right]^{-1}\left[\mathrm{ClO}_{4}{ }^{-}\right]^{-1}[\mathrm{TOPO}]_{\mathrm{org}}{ }^{-3}
\end{aligned}
$$

The value $\mathrm{K}_{\mathrm{ex}, 3(\mathrm{M})}$ for $\operatorname{sodium}(\mathrm{I})$ ion $^{1)}$ when the ionic concentration in the aqueous phase is $1 \mathrm{~mol} \mathrm{dm}^{-3}$ is $10^{1.01}$. Thus the free TOPO concentration at equilibrium was calculated by the following equation

$$
\begin{aligned}
& {[\mathrm{TOPO}]_{\mathrm{org}, \text { initial }}=[\mathrm{TOPO}]_{\mathrm{org}}+3\left[\mathrm{NH}_{4}(\mathrm{TOPO})_{3}{ }^{+} \mathrm{ClO}_{4}{ }^{-}\right]_{\mathrm{org}^{+}} 3\left[\mathrm{Na}(\mathrm{TOPO})_{3}{ }^{+} \mathrm{ClO}_{4}{ }^{-}\right]_{\mathrm{org}} } \\
= & {[\mathrm{TOPO}]_{\mathrm{org}^{+}}+3 \mathrm{~K}_{\mathrm{ex}, 3}\left[\mathrm{NH}_{4}{ }^{+}\right]\left[\mathrm{ClO}_{4}{ }^{-}\right][\mathrm{TOPO}]_{\mathrm{org}}{ }^{3}+3 \mathrm{~K} \mathrm{ex,3( \textrm {M } )}\left[\mathrm{Na}^{+}\right]\left[\mathrm{ClO}_{4}{ }^{-}\right]\left[\mathrm{TOPO}_{\mathrm{org}}{ }^{3}(7)\right.}
\end{aligned}
$$

Results and Discussion

The distribution ratios of ammonia and ammonium ion measured as a function of the initial TOPO concentration are given in Fig. 1. As is seen, the distribution ratio of ammonia is only slightly dependent on the TOPO concentration while that of anmonium ion is third order dependent. This TOPO dependence of the ammonia extraction was concluded to be due to the extraction of ammonium ions in an equilibrium with the ammonia in the aqueous solution in this $-\log \left[\mathrm{H}^{+}\right]$range (10.7 to 10.8). Figure 2 gives the dependence of the distribution ratio which is normalized for the change in the TOPO concentration by dividing $D$ by [TOPO] 3 (under these conditions where $\left[\mathrm{NH}_{3}\right] \ll\left[\mathrm{NH}_{4}^{+}\right], \mathrm{D}\left(\mathrm{NH}_{4}^{+}\right)\left[\mathrm{TOPO}_{\text {org }}{ }^{-3}=\mathrm{K}_{\mathrm{ex}, 3^{[}}\left[\mathrm{ClO}_{4}^{-}\right]\right.$as is seen from Eq. 5). Since a chloride ion is too small to be an effective counter-ion in an extractable ion-pair, the extraction in Fig. 2 is first order dependent on the perchlorate concentration. Thus the ammonium ions should be trisolvates with TOPO and extracted as ion-pairs with perchlorate ions, $\mathrm{NH}_{4}(\mathrm{TOPO})_{3}{ }^{+} \mathrm{ClO}_{4}{ }^{-}$. Figure 3 gives the dependence of the distribution ratio on the hydrogen-ion concentration. Under these conditions, the ratio $\left[\mathrm{NH}_{4}{ }^{+}\right]\left[\mathrm{NH}_{3}\right]^{-1}$ increases gradua ${ }^{-1}$ by increasing the hydrogen-ion concentration and consequently the distribution ratio also increases. From the data in Figs. 1 to 3 the values of the constants, $K_{e x, 3}, K_{d}$, and $K_{a}$ were calculated by using a least squares program on the basis of Eqs. 5 and 7. The values obtained are given in Table 1 . The solid curves in the figures were calculated by introducing these values into Eq." 5 .

In Fig. 1 the values of the experimentally obtained distribution ratio of ammonium ion in the higher TOPO concentration range are a little lower than those given by the calculated curve. The same type of deviation was also found in the extraction of other metal perchlorates with TOPO in hexane and this has been explained in terms of the change in the activity coefficient of the chemical species in the hexane phase in such a high TOPO concentration range. ${ }^{3}$ The deviation in Fig. 3 at lower pH region should also be due to the same reason. The 


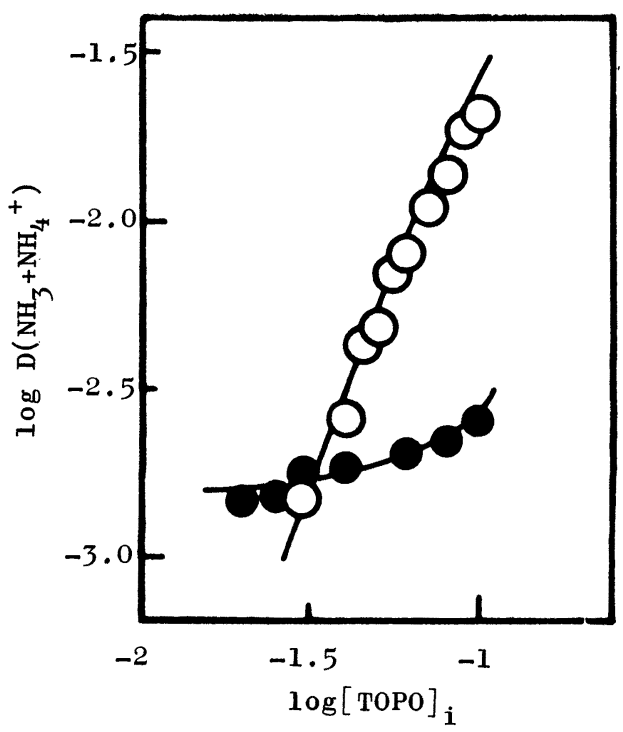

Fig. I The distribution ratio as a function of initial TOPO concentration. Org. phase; $1 \mathrm{~mol} \mathrm{dm}^{-3} \mathrm{NaClO}_{4}$, $\left[\mathrm{H}^{+}\right] /\left(\operatorname{mol} \mathrm{dm}^{-3}\right)=10^{-10.7}(\mathrm{O})$ and $10^{-4}(\mathrm{O})$. The solid curves are calculated by Eq. 5 using the constants in Table 1 .

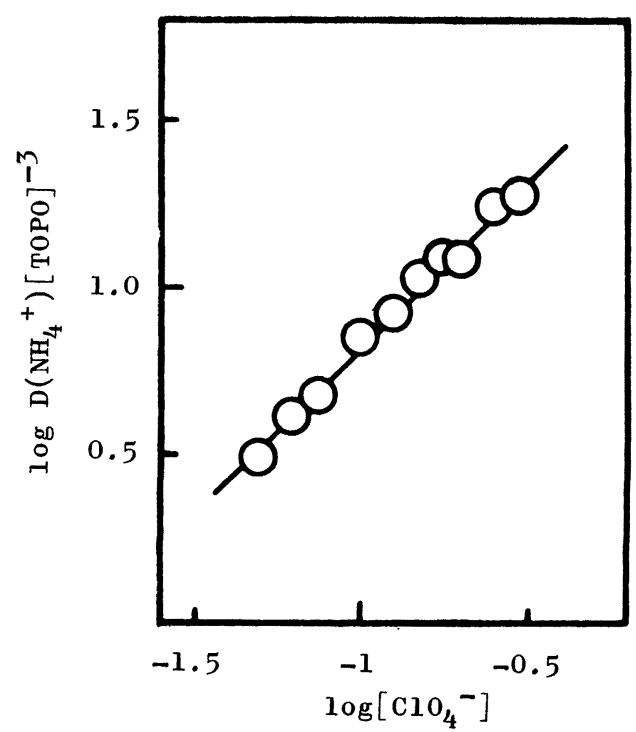

Fig. 2 The dependence of the distribution ratio of ammonium ion as a function of perchlorate in $1 \mathrm{~mol} \mathrm{dm}^{-3} \mathrm{Na}\left(\mathrm{Cl}, \mathrm{ClO} \mathrm{O}_{4}\right)$ at $\left[\mathrm{H}^{+}\right]=10^{-4} \mathrm{~mol} \mathrm{dm}^{-3}$. Org. phase; hexane containing $0.05 \mathrm{~mol} \mathrm{dm}^{-3}$ TOPO. The solid line is calculated by Eq. 5 using the constants in Table 1 .

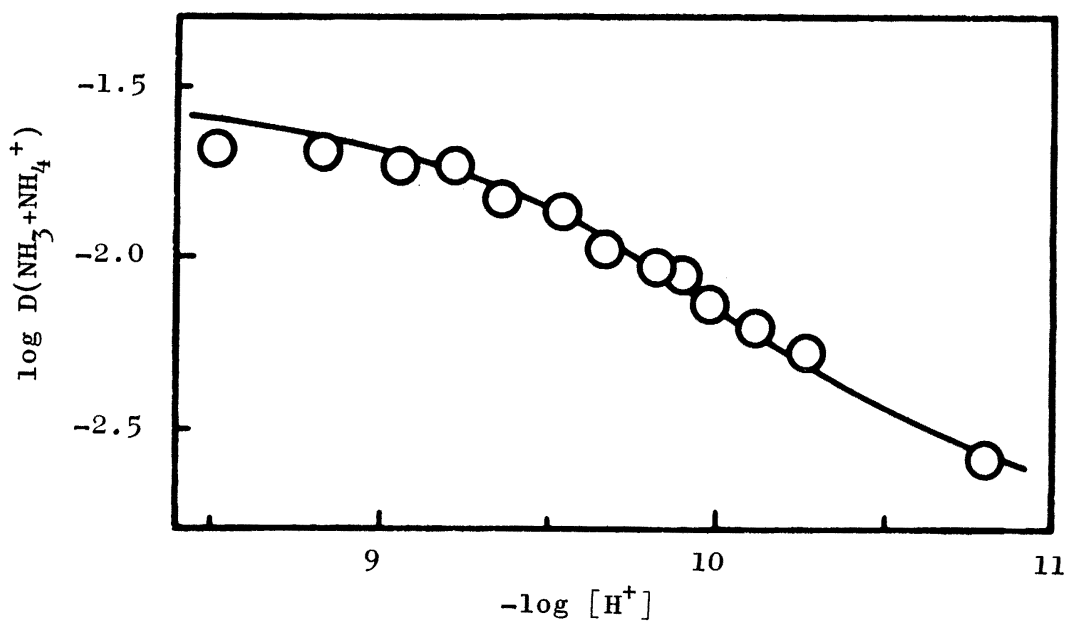

Fig. 3 The dependence of the distribution ratio of (ammonia plus ammonium) as a function of the hydrogen-ion concentration in 1 mol $\mathrm{dm}^{-3} \mathrm{NaClO}_{4}$. The organic phase was hexane containing $0.1 \mathrm{~mol} \mathrm{\textrm {dm } ^ { - 3 }}$ TOPO. The $-\log \left[\mathrm{H}^{+}\right]$of the aqueous phase was adjusted by adding various amounts of perchloric acid. The solid curve is calculated by Eq. 5 using the constants in Table 1 . 
Table 1. Equilibrium constants of ammonia and ammonium perchlorate at 298K. 0rg. phase; hexane containing TOPO, aq. phase; 1 mol $\mathrm{dm}^{-3} \mathrm{Na}\left(\mathrm{ClO}_{4}\right)$.

$\begin{array}{lc}\log \mathrm{K}_{\mathrm{ex}, 3} & 1.78 \pm 0.19 \\ \log \mathrm{K}_{\mathrm{a}} & -9.31 \pm 0.14 \\ \log \mathrm{K}_{\mathrm{d}} & -2.8\end{array}$

The range of error is $3 \sigma$.

The value of $K_{d}$ is somewhat more erroneous than the others and the limit of error is not given.
Table 2. Extraction constants of alkali metal. perchlorates with TOPO in hexane under identical conditions with those in Table 1 (taken from ref. 2).

\begin{tabular}{lccc}
\hline $\mathrm{M}^{+}$ & \multicolumn{1}{c}{ ionic radius } \\
pm & $\operatorname{logK}_{\mathrm{ex}, 3(\mathrm{M})}$ & $\operatorname{logK}_{\mathrm{ex}, 4(\mathrm{M})}$ \\
\hline $\mathrm{Li}^{+}$ & 60 & 2.29 & $\mathrm{nil}$ \\
$\mathrm{Na}^{+}$ & 95 & 1.01 & $\mathrm{nil}$ \\
$\mathrm{K}^{+}$ & 133 & 0.57 & $\mathrm{nil}$ \\
$\mathrm{Rb}^{+}$ & 148 & 0.06 & 0.99 \\
$\mathrm{Cs}^{+}$ & 169 & -0.17 & 0.95 \\
$\mathrm{NH}_{4}{ }^{+}$ & 143 & $1.78^{* *}$ & $\mathrm{nil}$ \\
\hline
\end{tabular}

* Taken from ref. 10. ** Present work.

value of acid dissociation constant of ammonium ion in 1 mol $\mathrm{dm}^{-3} \mathrm{Na}\left(\mathrm{ClO}_{4}\right)$ in the stoichiometric units is similar to literature values $\left(\mathrm{pK}_{\mathrm{a}}=9.265\right.$ at zero ionic

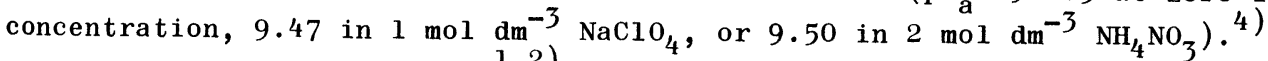

In the previous studies, ${ }^{1,2}$ trisolvates of alkali metal ions with TOPO were extracted into hexane with perchlorate ions though tetrasolvates were also found with rubidium(I) and caesium(I) (cf. Table 2). Ammonium ion was found to be extracted as trisolvate like as alkali metal ions. It is assumed that the TOPO molecules in the extracted alkali perchlorate species should solvate the central cation. However, the TOPO molecules should be more highly orientated around the ammonium ion than the other metal ions by tetrahedrally dispersed positive charge on the former. The following structure may be suggested for the extracted species, $\mathrm{NH}_{4}(\mathrm{TOPO})_{3}{ }^{+} \mathrm{ClO}_{4}{ }^{-}$; each of three TOPO molecules is bound with a hydrogen atom by forming a hydrogen-bond and the perchlorate ion locates closely to the fourth hydrogen atom which is not bound with TOPO.

It is generally observed among alkali ions that the larger the size, the better the extraction as ion-pairs into polar solvents. ${ }^{5)}$ When alkali and ammonium ions are extracted into nitrobenzene with dipicrylamine, the order of the extraction was reported to be $\mathrm{Li}^{+}<\mathrm{Na}^{+}<\mathrm{NH}_{4}{ }^{+}<\mathrm{K}^{+}<\mathrm{Rb}^{+}<\mathrm{Cs}^{+}$. 6) On the contrary when their solvates with TOPO (except $\mathrm{NH}_{4}{ }^{+}$) are extracted into non-polar solvents as ion-pairs with large anions, an opposite order is observed due to stronger solvation tendency of the smaller ions with the extractant. ${ }^{2}$ ) However, the order of the magnitude of the extraction constant in Table $2, \mathrm{Li}^{+}>\mathrm{NH}_{4}{ }^{+}>\mathrm{Na}^{+}>\mathrm{K}^{+}$, indicates that the extraction of ammonium ion with TOPO is somewhat better than is expected from its ionic size. This may be explained in terms of the formation of hydrogen-bond between TOPO and the hydrogen atom in ammonium ion.

It was observed in a previous study that the extraction of ammonium ions as a complex with dibenzo-18-crown-6 with a picrate ion was poorer than of potassium(I) and rubidium(I) and this was concluded to be mainly due to the smaller stability of the ammonium complex. ${ }^{7)}$ This instability of the complex may be understood by a 
steric effect. The complex contains the ammonium ion which has the tetrahedrally located four hydrogen atoms in the center of the macrocyclic polyether ring. Thus although the ionic radius of ammonium ion is similar to those of potassium and rubidium ion, its complex could be less stable than those of the two ions. On the other hand, there may not be such a problem in the formation of hydrogen-bonds between TOPO and the hydrogen atoms in ammonium ion. There is, however, another report that 18-crown-6 extracted ammonium ions as iodide into dichloromethane a little better than potassium(I).8)

The independence of the distribution ratio of ammonia from the TOPO concentration shows that though the hydrogen atom of ammonia might form hydrogenbonds with TOPO, they should not be enough strong as to allow an effective extraction. The interactions between the solvent molecules and ammonia should be weaker with hexane than several. other non-polar solvents as is seen from its solubilities in them. ${ }^{9}$ )

The present results indicate that when an aqueous sample solution contajning ammonium ion at high concentration is treated by extraction with a solvating type extractant, extraction of ammonium ion with large anions may occur and affect the results; it decreases the concentration of the free extractant which is available for the metal ions in the solution though the effect may not be very serious in many cases.

\section{References}

1) S. Kusakabe, T. Sekine: Bu11. Chem. Soc. Jpn., 53, 1759 (1980).

2) S. Kusakabe, T. Sekine: Bu11. Chem. Soc. Jpn., 53, 2087 (1980).

3) S. Kusakabe, T. Sekine: Bul1. Chem. Soc. Jpn., 54, 2930 (1981).

4) L. G. Sillén, A. E. Marte11: "Stability Constants", Special Publication No. 17 (1964) and No. 25 (1971), (The Chemical Society, London).

5) S. Kusakabe, T. Sekine: Nippon Kagaku Kaishi, 1981, 310.

6) J. Rais, M. Kyrš, M. Pivoňková: J. Inorg. Nucl. Chem., 30, 611 (1968).

7) Y. Hasegawa, H. Wakabayashi, M. Sakuma, T. Sekine: Bull. Chem. Soc. Jpn., 54, 2427 (1981).

8) S. Yanagida, K. Takahashi, M. Okahara: Bull. Chem. Soc. Jpn., 50, 1386 (1977).

9) H. Stephen, T. Stephen: "Solubilities of Inorganic and Organic Compounds", (1963), (Pergamon, 0xford). T. Sekine, Y. Hasegawa: "Solvent Extraction Chemistry", p. 128 (1977), (Dekker, New York).

10) L. Pauling: "The Nature of the Chemical Bond", 3rd Ed., p. 514 (1960), (Cornell University Press, New York). T. Moeller: "Inorganic Chemistry", p. 576 (1952), (John Wiley, New York).

\section{Keyword phrases}

solvent extraction of $\mathrm{NH}_{3}$ and $\mathrm{NH}_{4}{ }^{+}$with trioctylphosphine oxide; ion-pairs of $\mathrm{NH}_{4}^{+}$and perchlorate ion; trioctylphosphine oxide extractions of $\mathrm{NH}_{4}^{+}$and alkal.i icns; $\mathrm{pK}_{\mathrm{a}}$ of ammonium ion. 